\title{
Effects of Data Uncertainties on Estimated Soil Organic Carbon in the Sudan
}

\section{JEAN-NICOLAS POUSSART JONAS ARDÖ*}

Department of Physical Geography and Ecosystem Analysis Lund University

Sölvegatan 12

S-223 62, Lund, Sweden

\section{LENNART OLSSON}

Center for Environmental Studies

Lund University

Box 170

S-221 00, Lund, Sweden

ABSTRACT / Estimating the rate of soil carbon sequestration in degraded semiarid agroecosystems is of great interest due to the beneficial effects on soil properties, soil fertility, and the potential atmospheric $\mathrm{CO}_{2}$ mitigation. One of several applied methodologies, biogeochemical modeling, offers possibilities to distribute estimates of soil organic carbon (SOC) over re- gions, estimate the effects of changes in climate and ecosystem management on SOC, and quantify changes of soil properties over time or space. In this study, the sensitivity of the Century model was assessed in regards to uncertainties for soil texture, natural fire return periods, grazing intensities, and climate. The study area was situated in central Sudan and dominated by subsistence agroecosystems. Uncertainties in the modeling of historical SOC levels, prior to known human interactions, can be reflected in the estimation of the current or future SOC levels, as some soil processes take many years to occur. The relationship between these differences in historical and current SOC levels was calculated. Soil texture, derived from a number of different sources, had the greatest impact on modeled SOC. Overall, data uncertainties for the five parameters tested resulted in SOC variations of up to $160 \mathrm{~g}$ $\mathrm{C} / \mathrm{m}^{2}(1.6 \mathrm{t} \mathrm{C} / \mathrm{ha})$ for the estimation of the current level (year 2002), which corresponds to a difference of approximately $80 \%$ of the average current level.
Increasing carbon (C) sequestration in terrestrial ecosystems could help counteract land degradation and mitigate the increasing rate of atmospheric $\mathrm{CO}_{2}$ (IPCC 2000, Lal 2001, Olsson and Ardö 2002). Large parts of the world's semiarid areas are degraded (UNEP 1992, Lal 2001) and vulnerable to environmental changes (Warren and others 1996). Soil organic matter (SOM) content in drylands is usually low in places where land degradation is severe. The potential to increase soil C content through improved land management practices may therefore be high. The issue of carbon sequestration is present in three international conventions: the UN Framework Convention on Climate Change (UNFCCC), the UN Convention to Combat Desertification (UNCCD), and the UN Convention on Biodiversity (UNCBD) (Olsson and Ardö 2002).

In the Sahel, the increasing demand for food can encourage farmers to reduce the length of fallow periods, cultivate continuously, overgraze fields, or remove

KEY WORDS: Soil organic carbon; Sequestration; Semiarid; Modeling; Century; Uncertainties; Sudan

Published online March 4, 2004.

*Author to whom correspondence should be addressed, email: jonas.ardo@nateko.lu.se much of the above-ground biomass through fuel collection or for building materials. Such practices can result in the reduction of soil organic carbon (SOC), water holding capacity, nutrients, as well as promote soil erosion (Lal 2002). Increasing the soil organic matter could help reverse these problems and may be crucial for future African agriculture and food production (Bationo and Buerkert 2001, Sanchez 2002).

The modeling of SOC dynamics complements direct sampling when estimating historical and current SOC levels, as well as $\mathrm{C}$ sequestration potential. Modeling provides the following advantages: (1) estimates the effects of changes in climate and ecosystem management on SOC, (2) may be used to distribute SOC estimates to a regional level, and (3) quantifies changes over both time and space (Paustian and others 1997, Ardö and Olsson 2003a).

Models vary in structural complexity. Ecosystemlevel models usually consider multiple organic matter fractions (pools) to account for variability in the decomposability of different organic compounds and are therefore run in data-rich environments (Paustian and others 1997). Knowing a model's sensitivity to variations and uncertainties in input data and its key parameters is of importance for judiciously choosing adequate input data, as well as for improving interpretation 
of the results. Sensitivity analyses can also be useful to improve data collection methods (Ardö and others 2000).

All data are impaired with uncertainties, often divided into random errors and systematic errors. A random error refers to the uncertainty that occurs due to the apparent, possibly inherent, randomness of the entities observed, but also to the precision and accuracy of the measurements performed. Empirical quantities are also impaired by systematic errors that are due to biases in the applied measurement devices and the experimental procedures, as well as inaccuracies associated with value judgments.

Century is an ecosystem model commonly used to simulate soil-plant nutrient dynamics (Parton and others 1987, 1988, Metherell and others 1993). The model has been widely used and validated (Burke and others 1989, Parton and others 1993, 1994, 1996, Bromberg and others 1996, Smith and others 1997) including studies in the Sudan (Olsson and Ardö 2002, Poussart 2002, Ardö and Olsson 2003a, 2003b). During modeling, the historical amounts of soil $\mathrm{C}$ (prior to known human influence on the land) are frequently established by running the model to equilibrium. This can be done by, for example, using long-term climate averages and reconstructing native land cover and historical land use (Ojima and others 1993, Adderley and others 2000, Mitchell and Csillag 2001, Pennock and Frick 2001). By native land cover we mean undisturbed vegetation (savanna/grassland) comprised of acacias and $\mathrm{C}_{4}$ grasses. Often, human activities such as cultivation, are not considered for running the model to equilibrium because the purpose of the modeling exercise is to estimate the impacts of human interactions, as well as climate and atmospheric $\mathrm{CO}_{2}$ changes on nutrient cycling and/or SOC. The scheduling of when events occur during simulations can affect the size of these historical C pools, at which SOC is considered to be in steady state. Land use and land management practices, as well as land cover, also impact SOM in different pools. Differences in historical pools can affect the results of simulated SOC several years later. For example, in an experiment using Century, the soil $\mathrm{C}$ level, originally at a steady state value of $5500 \mathrm{~g} \mathrm{C} / \mathrm{m}^{2}$ with annual input of $400 \mathrm{~g} \mathrm{C} / \mathrm{m}^{2} / \mathrm{yr}$, took 220 years to reach $90 \%$ of the new equilibrium value once the $\mathrm{C}$ input changed to $200 \mathrm{~g} \mathrm{C} / \mathrm{m}^{2} / \mathrm{yr}$ (Paustian and others 1997). This reflects the importance the equilibrium values can have on simulation results. Robert (2001) noted that, theoretically, a given soil type exposed to a constant practice normally reaches equilibrium in SOM content after 30-50 years. Lal (2001) also discusses the potential of $\mathrm{C}$ sequestration in degraded lands and states that
C sequestration can continue for up to 150 years, although the peak of sequestration is reached within the first 10-15 years after conversion to improved land management practices. Accurate historical records of land management and land cover can be difficult to obtain in many developing countries, including the Sahel region. Many assumptions are therefore required to model the historical SOC levels. A dynamic model of land use changes in Sudano-Sahelian countries has previously been proposed to deal with some of these difficulties (Stephenne and Lambin 2001).

The objective of this study is to examine and quantify the impacts of data uncertainties on SOC simulated with the Century model in the semiarid agroecosystems of the Sudan. More specifically, uncertainties for soil texture, natural fire return periods, grazing intensities, and climate are investigated. This is accomplished by: (1) simulating SOC for different historical scenarios, resulting from data uncertainties; and (2) quantifying the effect of different historical SOC levels on modeled SOC for the year 2002.

\section{Methodology}

\section{The Study Area}

The study area is in the province of Kordofan, in central Sudan. Soils found in the area are Haplic xerosols, Chromic vertisols, Chromic luvisols, and Lithosol/Eutric cambisols, but the most common is a Cambic Arenosol (FAO-Unesco 1995), locally named Qoz. This is a coarse-textured sandy soil of aeolian origin and poor in clay content (Warren 1970, Craig 1991, Zaroug 2000).

The climate is semiarid with a mean annual rainfall of $270 \mathrm{~mm}$. Precipitation is concentrated in the summer months (June to September) and distributed over only a few, intense events. The mean annual temperature is $29^{\circ} \mathrm{C}$ with January being the coldest month and May the warmest (Olsson 1985a).

The land use is characterized by pastoral and transhuman grazing, usually combined with traditional rainfed cultivation. The most common rainfed crops on these Qoz soils are millet (Pennisetum typhoideum), sesame (Sesamum indicum), sorghum (Sorghum vulgare), and groundnuts (Arachis hypogaea) (Craig 1991). From the literature (Jewitt and Manton 1954, Davies 1985 , Haaland 1991, Khogali 1991, Olsson and Rapp 1991) and interviews with local farmers, it is evident that the land use practices have changed noticeably during the last few decades (Olsson and Ardö 2002). Rotation systems with long fallow periods (15-20 years) interspersed with short periods of cultivation (4-5 years) 
Table 1. Modeled base scenario

\begin{tabular}{ll}
\hline Time period (crop:fallow ratio) & Management (land use) \\
\hline 3000 BC-1890 & $\begin{array}{l}\text { Native vegetation (grassland \& trees) } \\
\text { Annual grazing from June to December } \\
\text { Natural fire every nine years (February) }\end{array}$ \\
$\begin{array}{l}\text { Cultivation of millet } \\
\text { Cropping year }\end{array}$ & $\begin{array}{l}\text { Grazing (low) in Oct. to Dec. after harvest } \\
\text { 85\% of aboveground biomass (straw) removed during harvest }\end{array}$ \\
$1915-1955(5: 15)$ & Fire every year prior to planting \\
$1956-1975(3: 7)$ & Trees (Acacia senegal) allowed growing \\
Fallow year & Low grazing all year round \\
$1976-1985(7: 3)$ & Anthropogenic fires every five years \\
\end{tabular}

have been replaced to what is more or less continuous cropping today. Continuous cultivation exhausts these soils causing a sharp drop in fertility and declining productivity (Zaroug 2000, Bationo and Buerkert 2001). Mainly camels, sheep and goats graze the area, but cattle are also found further south, as the precipitation increases. Migratory seasonal grazing with large variations from year to year is common (Olsson 1985b).

Natural and anthropogenic fires occur regularly in the area. It is common practice to burn the cropland annually prior to planting, which occurs in June or July. Previous studies observed natural fire return intervals for this and similar environments to range from 1 to 12 years (Scholes and Walker 1993, Sitch 2000).

\section{The Century Model}

The Century model is a general model of plant-soil nutrient cycling, which can be used to simulate carbon and nutrient dynamics for different types of ecosystems including grasslands, agriculture lands, forests, and savannas (Parton and others 1987, Metherell and others 1993). The model runs at a monthly time step, functions at the scale of a square meter (i.e., point basis), and simulates the upper $20 \mathrm{~cm}$ of the soil profile. Driving variables include monthly precipitation and monthly average minimum and maximum temperatures. The soil texture, litter nitrogen $(\mathrm{N})$, and lignin content of plant material are also important parameters controlling the soil processes. The soil organic matter (SOM) is calculated for three pools with different decomposition rates. The active pool represents microbial biomass and microbial products and has a short turnover time of months to a few years. The slow pool contains a fraction of the SOM that is physically protected and/or in chemical forms with more biological resistance to decomposition and has an intermediate turnover time of $20-50$ years. The passive pool repre- sents the fraction that may be both physically and chemically protected and has turnover times of 4002000 years. The model uses first order equations to simulate all SOM pools, and the soil moisture and temperature are key factors modifying transformation rates. In agroecosystem simulations, management-related driving variables can be incorporated. Information can be specified for crop rotations, dates of planting and harvesting, weeding, fertilizer and manure application, grazing, irrigation, fire, tillage practices, and erosion.

\section{Simulating SOC with the Century Model}

Climate data from the meteorological station in Bara $\left(13^{\circ} 42^{\prime} \mathrm{N}, 30^{\circ} 30^{\prime} \mathrm{E}\right)$ were used for the simulations (Century version 4.0 ), as this is the closest station to the study area. The data available ranged from 1908 to 1988. For missing data within the observation period or for simulations outside the time span of the data, mean values of all observations available for the related month were used. Other site-specific parameters, such as soil bulk density (approximately $1.7 \mathrm{~kg} / \mathrm{dm}^{3}$ ) and texture, were determined with soil samples. These samples were taken from a cultivated field (millet), a field in fallow and a grazing field in February 2001.

A base scenario of land use and management, together with native land cover, was developed to allow direct comparison of the effects associated to different data uncertainties (Table 1). The historical amounts of soil C (before human interactions) were established by running the model to equilibrium using long-term climate averages from the available climate data (from $3000 \mathrm{BC}$ to 1890 ). The output SOC value examined was the sum of the $\mathrm{C}$ found in the three SOM pools (active, slow, and passive). Land use and management were simulated using the best available data based on field interviews, literature (Jewitt and Manton 1954, DOXIA- 


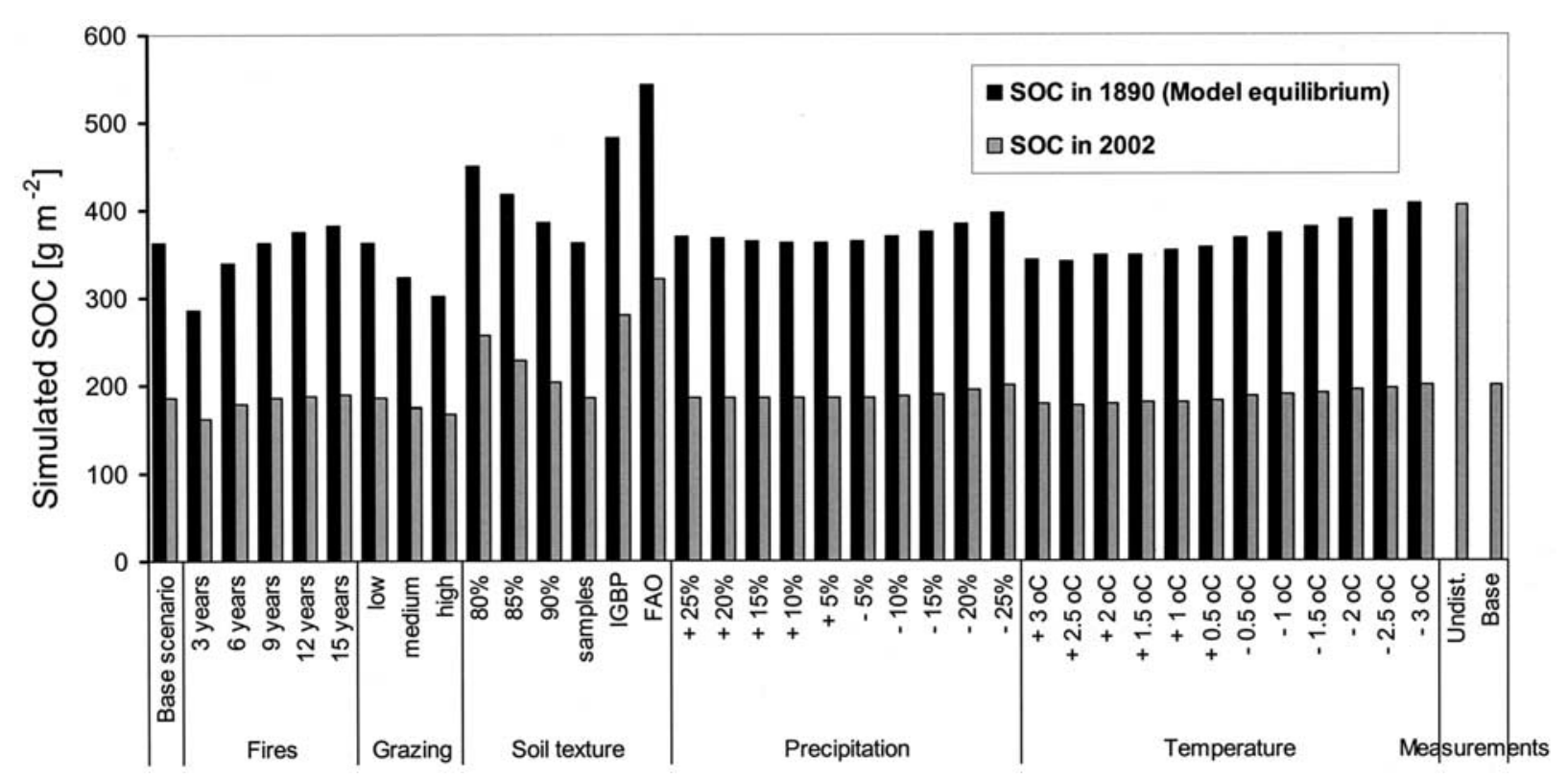

Figure 1. Soil organic carbon (SOC) simulated with Century for a semiarid agroecosystem of the Sudan. Detailed scenario is described in text. Shown are the SOC levels at model equilibrium (before 1890) and for year 2002. Measurements for sites representative for the base scenario (mean of 4 sites) and for undisturbed sites (mean of 3 sites) are included to the far right.

DIS 1964, Pacheco and Dawoud 1976, Davies 1985, Olsson 1985b, Stern 1985, Ahlcrona 1988, Alstad 1991, Craig 1991, Haaland 1991, Khogali 1991, Olsson and Rapp 1991) and approximations of events typical for the area (Ardö and Olsson 2003a). The equilibrium of the model was achieved by 1890, as before this date, human activities, such as cultivation and harvest were not simulated. The vegetation in the area was assumed to be undisturbed by human interference prior to 1890 $\left(\mathrm{C}_{4}\right.$ grassland with trees, such as Acacia senegal $)$. Grazing occurred annually from June to December, when vegetation was abundant. Natural fires occurred every 9 years during the dry season, in February. Human impacts, other than grazing, were assumed to start in 1891.

In the base scenario, millet was cultivated on the land with a 5:20 crop-fallow ratio between 1891 and 1915. Grazing occurred from October to December, after harvest of the millet each cropping year. During fallow years, light grazing took place all year round. Anthropogenic fires were set annually prior to the planting of the crops, otherwise they occurred every fifth year during the fallow periods. The above-ground biomass (straw) removed during harvest equaled $85 \%$, as straw is an important building material in the area and is also collected as fodder for the dry season. These practices remained the same throughout the simulations, up to year 2002, except for changes in the cropfallow ratios. The crop-fallow ratios used as of 1916 were 5:15 (1916-1955), 3:7 (1956-1975), 7:3 (19761985), and 4:6 (1986-2002). Trees (Acacia senegal) were allowed to grow during fallow periods.

SOC measurements from three undisturbed sites and from four sites representing our base scenario are included for comparison (Figure 1). Undisturbed sites were sites without signs of cultivation that were located far from villages selected, see (Ardö and Olsson 2003a, 2003b) for details about soil sampling and soil analysis.

\section{Data Uncertainties}

All levels of uncertainty presented below are aimed to represent the uncertainties and variation found in literature and existing data sets.

Soil texture. Soil texture influences many processes simulated in the Century model, such as the SOM turnover and stabilizing rates, field capacity, wilting point, soil water evaporation, and N leaching (Burke and others 1989, Metherell and others 1993, Paustian and others 1997). The different fractions composing the soil samples extracted in the study area averaged 93\% sand, $4 \%$ silt, and 3\% clay. These values were used in the simulations testing the effects of other parameters (grazing intensity, fire return periods, and climate). In cases where distributed modeling is performed or if SOC distributions are to be scaled-up to a regional level, soil texture may be derived from available digital global soil databases (Ardö and Olsson 2003a). Such databases are the Food and Agriculture 
Table 2. Percentages of live shoots and standing dead biomass removed by simulated grazing events

\begin{tabular}{llll}
\hline & \multicolumn{2}{l}{ Grazing } & \\
\cline { 2 - 3 } & Low & Medium & High \\
\hline Live shoots removed $(\%)$ & 10 & 20 & 30 \\
Dead biomass removed $(\%)$ & 5 & 10 & 15 \\
\hline
\end{tabular}

Organization of the UN (FAO) Soil Map of the World (FAO-UNESCO 1995) and the Soil Data Task of the International Geosphere-Biosphere Programme (IGBP) (Global Soil Data Task 2000)

For the FAO Soil Map of the World, the soil texture for the study area was derived by the area-weighed mean of the texture of all soil associations, for the dominant soil type Cambic arenosol, and equaled 57\% sand, 30\% silt, and 13\% clay (Ardö and Olsson 2003a). The texture derived from the IGBP Soil Data Task states a particle size distribution of $72 \%$ sand, $16.9 \%$ silt, and $11.1 \%$ clay. Both of these soil textures were tested, as well as hypothetical soil textures of $80 \%, 85 \%$, and $90 \%$ sand, dividing the remaining fraction equally for the silt and the clay.

Fire frequencies Prior to 1890 , natural fires were simulated using fire return periods of $3,6,9,12$, or 15 years. For the base scenario designed to test the sensitivity of other parameters, the return period was set to nine years (Scholes and Walker 1993, Parton and others 1996, Sitch 2000).

Grazing intensity. Variations in grazing intensities were considered while modeling the equilibrium of the historical C pools (before 1890). Low, medium, and high intensities were used in the simulations. The removal of live shoots and dead standing biomass by the grazing events differentiates their impact in the model (Table 2). For the three intensities, the effect of grazing had a linear impact on production (Metherell and others 1993).

Climate. The annual precipitation follows a strong north-south gradient (Ahlcrona 1988, Nicholson 2000, Hulme 2001) with drier areas north of the study site and wetter areas to the south. From approximately a $2^{\circ}$ difference in latitude north and south of the study area, the annual rainfall ranges from less than $200 \mathrm{~mm}$ in the north to about $800 \mathrm{~mm}$ in the south. To investigate climate uncertainty on SOC at the study site, the mean values from Bara were directly modified to simulate differences in annual precipitation of up to $\pm 25 \%$ (every $5 \%$ difference) and minimum/maximum temperatures of up to $\pm 3^{\circ} \mathrm{C}$ (every $0.5^{\circ} \mathrm{C}$ difference).

\section{Relating Historical Soil C Pools to Present SOC} Status

Different scenarios (i.e., different soil textures, fire return periods, grazing intensities, and climate) lead to different levels of model equilibrium (defined as the level in 1890, i.e., before the introduction of cultivation). To evaluate the relationship between historical $\mathrm{C}$ pools and the resulting current (2002) SOC levels in the different scenarios, the equilibrium (1890) values of each simulation were compared to its modeled SOC level for year 2002. Once all simulations were completed $(N=36)$, the differences between all 36 runs and the lowest equilibrium value were calculated. In this way, all differences resulting from data uncertainties would be positive. A similar subtraction was done for the SOC levels in year 2002, calculating the differences based on the scenario that had the lowest equilibrium. Because the same base scenario was used between 1891 and 2002, it was anticipated that the lowest historical C pool would most probably also result in the lowest SOC for the year 2002. The calculated differences were thereafter plotted on a scatter plot and fitted with a polynomial trend line of the second order. This trend line describes the relationship between the relative differences in historical $\mathrm{C}$ pools and the relative differences of SOC in year 2002, based on the uncertainties of all parameters tested. The range (difference between highest and lowest) of equilibrium values for each individual parameter can then be used to describe the potential uncertainty associated with the parameter in question, in relation to this trend line (Table 3).

\section{Results}

The results of SOC at model equilibrium (1890) and simulated for year 2002, for all scenarios tested, are presented in Figure 1. The base scenario modeled indicates that the land management practices have led to a loss of SOC over the past century. Based on the averages, approximately $180 \mathrm{~g} / \mathrm{m}^{2}(1.8 \mathrm{t} \mathrm{C} / \mathrm{ha})$ of SOC were lost over the last 112 years, equal to $1.6 \mathrm{~g} / \mathrm{m}^{2} / \mathrm{yr}$ or approximately half of the historical level (1890).

The largest uncertainty on modeled SOC was caused by the soil texture (Figure 3). At model equilibrium SOC simulated with the soil texture from the FAO soil Map of the World was 50\% higher than SOC simulated with data based on soil samples $\left(\mathrm{FAO}=542 \mathrm{~g} / \mathrm{m}^{2}\right.$; soil samples $=362 \mathrm{~g} / \mathrm{m}^{2}$ ). When using data from the IGBP Soil Data Task, SOC at equilibrium equaled $483 \mathrm{~g} / \mathrm{m}^{2}$, equivalent to a SOC $33 \%$ more than with the soil samples.

As the return periods of natural fires became shorter, the SOC decreased. Nonetheless, the effects of 
Table 3. Overview of data uncertainties on modeled SOC

\begin{tabular}{ll}
\hline Data/parameter & Simulations \\
\hline Soil texture (\% sand, \% silt, \% clay) & FAO Soil Map of the World $(57,30,13)$, \\
& IGBP Soil Data Task $(72,16.9,11.1)$, \\
& Soil samples $(93,4,3)$, \\
& Hypothetical textures $(80,10,10),(85,7.5,7.5)$ and $(90,5,5)$ \\
Fires (return periods, years) & Ranging from 3 to 15 years $(3,6,9,12$ and 15) \\
Grazing intensities & Low, medium and high \\
Precipitation & $-25 \%,-20 \%,-15 \%,-10 \%,-5 \%,+5 \%,+10 \%,+15 \%,+20 \%$ and $+25 \%$ \\
& of monthly averages. \\
Temperature (min. \& max.) & $-3.0^{\circ} \mathrm{C},-2.5^{\circ} \mathrm{C},-2.0^{\circ} \mathrm{C},-1.5^{\circ} \mathrm{C},-1.0^{\circ} \mathrm{C},-0.5^{\circ} \mathrm{C},+0.5^{\circ} \mathrm{C},+1.0^{\circ} \mathrm{C},+1.5^{\circ} \mathrm{C}$, \\
& $+2.0^{\circ} \mathrm{C},+2.5^{\circ} \mathrm{C}$ and $+3.0^{\circ} \mathrm{C}$ of monthly averages \\
\hline
\end{tabular}

Figure 3. The differences between each simulation $(N$ $=36$ ) versus the lowest simulated SOC (base scenario with natural fires every third year). Consequently, the effects of other parameter uncertainties are positive.
SOC in Historical Pools vs. SOC in 2002

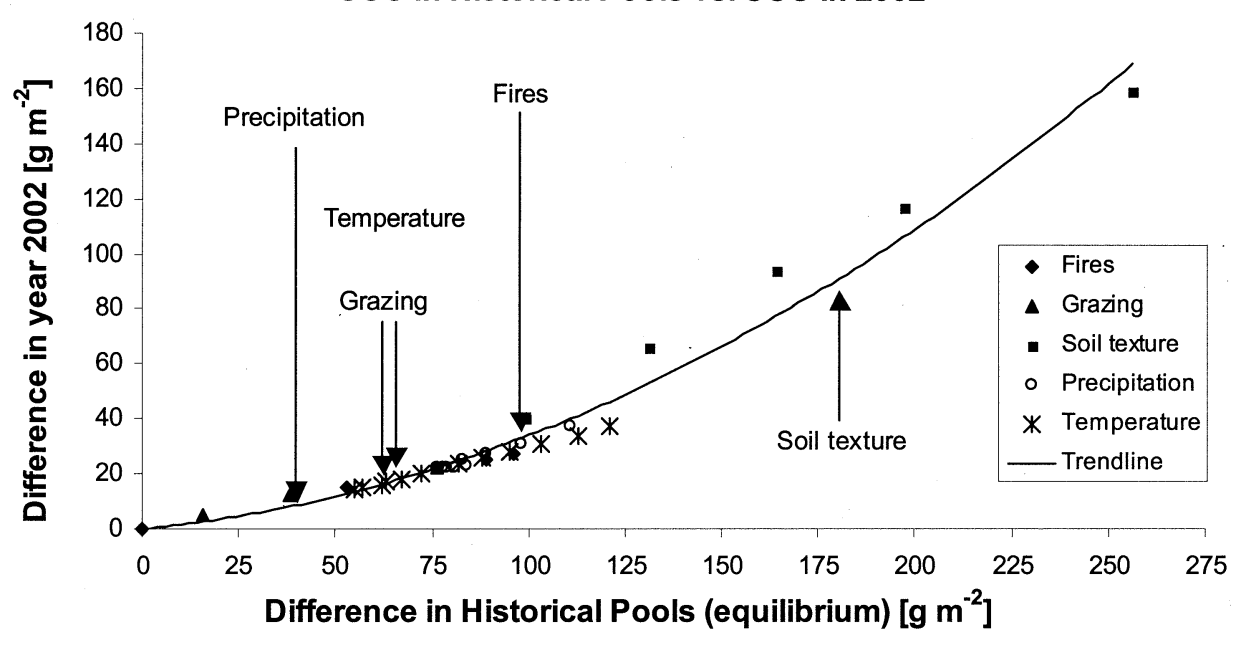

fires were not linear. For example, the difference in SOC at model equilibrium (1890) resulting from fires every third or sixth year was $53 \mathrm{~g} / \mathrm{m}^{2}$, whereas the difference between fires every twelfth or fifteenth year was $7 \mathrm{~g} / \mathrm{m}^{2}$.

Increasing grazing intensity decreases SOC. Less annual precipitation, as well as a colder annual temperature, both resulted in more SOC.

Figure 2 illustrates the range of simulated SOC for each data uncertainty tested. From the base scenario (Table 1), the uncertainties for soil texture, precipitation, and temperature are mainly positive (increased accumulation of SOC). On the other hand, uncertainties for grazing and variations in fire return periods mostly resulted in less SOC.

Figure 3 describes the relationship between the uncertainties of the modeled historical soil (1890) and consequences for the results of the SOC modeled for year 2002. Even with the assumptions that the model and the scenario simulated between 1891 and 2002 are correct, uncertainties for the five parameters tested could cause differences of up to $160 \mathrm{~g} / \mathrm{m}^{2}(1.6 \mathrm{t} \mathrm{C} / \mathrm{ha})$ in year 2002 (equal to approximately $80 \%$ of average current level). The possible effects of the individual parameters are also displayed based on the range of SOC levels each parameter generated.

\section{Discussion}

The SOC content in semiarid agroecosystems of the study area is currently very low $(\leq 1 \%)$. Changes over time or space of SOC contents will need to be estimated as accurately as possible if these changes are to be accounted for within carbon sequestration programs (Kyoto Protocol 1997, McDowell 2002). Ecosystem models, in combination with field measurements, are frequently used to estimate SOC distributions at a regional level (Falloon and others 1998, 2002, Ardö and Olsson 2003a). Models, such as Century, are the product of many years of research and are structurally com- 
Range of Simulated SOC Related to Data Uncertainties

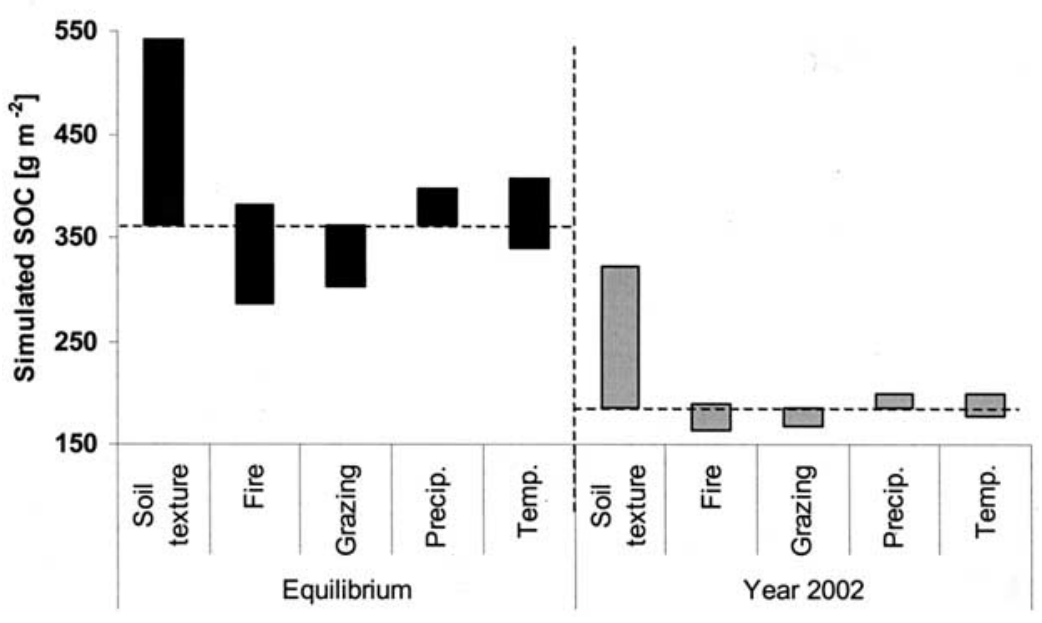

Figure 2. The range of the simulated SOC at model equilibrium and for year 2002, based on results presented in Figure 1. The dashed horizontal lines represent the base scenario (Table 1). plex. Difficulties for users of such models include successfully quantifying input data/parameters and creating land management scenarios that reflect reality as closely as possible. Neither of these two tasks is easily accomplished for the Sahel region of Africa, as written documentation often lacks.

Some soil processes take years to occur (i.e., decomposition, mineralization). Consequently, events taking place at a given time within a modeled scenario will affect the results of SOC several years later. The time needed to decompose the soil organic matter is influenced by the size of each organic matter pool (i.e., in Century, active, slow, and passive pools), which may be affected differently for various events and scenarios. Thus, the key question of this investigation was: How does the uncertainty of key parameters used to simulate the historical soil status affect the results of the current SOC level, assuming that the base scenario reflects the correct land management?

The soil texture derived from the FAO soil map differs from the soil texture measured at the study site. The sand fraction from the soil samples equaled $93 \%$, while for the FAO data, the same fraction represented only $57 \%$. The turnover of active SOM and the formation of passive SOM are mediated by soil clay content (higher in clay soils) (Metherell and others 1993). This explains why SOC simulated with soil data from FAO is much greater. The texture from the IGBP Soil Data Task was slightly better for the study area, but yet had $21 \%$ less sand than the soil samples. Other more detailed digital soil databases or maps of high spatial resolution, including soil texture, are not available for the area, which may be true for most developing countries. Hence, the FAO or IGBP digital compilations will most probably be used for distributed modeling or parameter estimation on a regional level. As a result, soil texture remains a limiting factor for accurate modeling of $\mathrm{C}$ sequestration in this region.

In Century, fires have several impacts. For example, they increase the root/shoot ratio, increase the $\mathrm{C} / \mathrm{N}$ ratio of live shoots, remove vegetation, and return inorganic nutrients to the soils (Metherell and others 1993). A higher fire frequency resulted in less accumulated SOC. The main effects of grazing in Century are to remove vegetation, return nutrients to the soil, alter the root/shoot ratio, and increase the nitrogen content of living shoots and roots (Metherell and others 1993). Even to this day, semipastoral farmers live in the area. Not many of the fields are fenced off, which makes it difficult to identify unique grazing fields or even estimate the pressure the animals generate on the grasslands. Also, different animals, such as goats, sheep, and camels, do not graze with the same intensity, and their impacts on the fields differ. Generally, goats graze much more intensely and therefore eat more aboveground vegetation than sheep (Humphreys 1978, Devendra and McLeroy 1982). In a recent improved land management project in Bara, one goal was to reduce the number of goats to replace them with sheep, in order to decrease the impact on the grazing areas (Anonymous 1999), a policy that appears relevant in the light of the results of this study.

Modeling with constant mean values for precipitation could be seen as somewhat unrealistic considering that central Sudan experienced important variations in annual precipitation totals during the last century (Ahlcrona 1988, Elagib and Mansell 2000, Nicholson 2000, Hulme 2001). Nevertheless, it remains a common and often applied method to simulate ecosystem behavior outside the time range of available climate data (Ojima 
and others 1993, Adderley and others 2000). The changes in precipitation examined in this study ranged by up to $\pm 25 \%$. Ahlcrona (1988) studied climate data from 1900 to 1986 for climate stations in central Sudan, and annual standardized precipitation totals varied from $\pm 200 \%$ from the mean, with many years varying by at least $50 \%$ (both above and below the mean). This shows that constant long-term monthly averages can easily over or underestimate climate values for a specific year. On the other hand, large annual deviations from a long time average will have a small impact on SOC content due to the long residence time of the SOC; Mitchell and Csillag (2001) also tested the effects of climate variability on grassland productivity in Saskatchewan, Canada, using the Century model. They concluded that changes in the variability of monthly precipitation had a greater impact on uncertainties when simulating net primary production (NPP) than constant variations in precipitation across time, not altering the variability of the monthly values. The maximum interannual precipitation variation tested was $25 \%$, which represents a deviation of $68 \mathrm{~mm}$ from the long-term annual average. The SOC in 2002 ranged by approximately $15 \mathrm{~g} / \mathrm{m}^{2}$ for these maximum deviations (Figures 1, 2, 3). The general trend for precipitation shows that less rainfall decreases decomposition, which consequently causes more SOC to accumulate. This result appears to contradict the belief that SOC increases with rainfall but is in accordance with similar results obtained when modeling the effects of climate change on grassland soil C storage (Ojima and others 1993). In a simulation for a site in Khartoum, Sudan, they found that climate change (increased temperature and precipitation) could cause the grasslands to become sources of $\mathrm{C}$, even if the annual aboveground plant $\mathrm{C}$ would increase. The impact of temperature variations on SOC were similar to those of precipitation. The effects of temperature on decomposition increase as soil temperature increases (Metherell and others 1993). For variations of $\pm 3{ }^{\circ} \mathrm{C}$, SOC in 2002 ranged by $23 \mathrm{~g} / \mathrm{m}^{2}$ (Figures $1,2,3$ ).

In a previous analysis of Century for the same study area, SOC was shown to be very sensitive to the rates of symbiotic N fixation from trees (Poussart 2002). N-fixing trees, such as Acacia senegal, are very common in the semiarid grasslands of the Sudan. It is very difficult to accurately estimate the rates of $\mathrm{N}$ fixation in the field. For this reason, $\mathrm{N}$ fixation from Acacia senegal was not simulated in this study. The results from Poussart (2002) suggest that SOC increases with increasing $\mathrm{N}$ fixation rates. More $\mathrm{N}$ in the system will decrease nutrient stress on the tree, and more tree growth will occur (Cindy Keough, NREL, Colorado State University, personal communica- tion, October 2002). Consequently, more soil organic matter is created as tree growth increases.

IPCC estimated the potential of $\mathrm{C}$ sequestration in the tropical dry ecozone to $10-30 \mathrm{~g} / \mathrm{m}^{2} / \mathrm{yr}$ for croplands and 10-150 $\mathrm{g} / \mathrm{m}^{2} / \mathrm{yr}$ for grasslands, depending on management (IPCC 2000). Because the study area is on the dry side of this tropical dry ecozone, the $\mathrm{C}$ sequestration potential is at the lower end of these intervals. Yet, these figures are slightly higher than those estimated by Ardö and Olsson (2003b), who approximated $\mathrm{C}$ sequestration potential at $4 \mathrm{~g} / \mathrm{m}^{2} / \mathrm{yr}$ for the first 50 years, or $3 \mathrm{~g} / \mathrm{m}^{2} / \mathrm{yr}$ after 100 years of cropland reverted to grazed rangeland. It should be noted that the $\mathrm{C}$ sequestration potentials presented above are valid for soils only and do not take into consideration additional sequestration in biomass. Sequestration rates are highest during the first period after conversion to an improved system and may peak within 10-15 years and then decline even if sequestration can occur for 50 years or more (Lal 2001).

Considering that current SOC values and changes over short periods of time are low, the results from this sensitivity analysis suggest that estimating historical, current, or future SOC levels for the Sahel remains difficult because of data uncertainties. Many of the events incorporated in the modeled scenarios are based on literature and interviews (Olsson and Ardö 2002, Ardö and Olsson 2003a) as site-specific detailed information often is lacking. Nonetheless, if the model can respond to changes in management, it increases its usefulness for the development of adequate future $\mathrm{C}$ sequestration projects. Improved grazing and fire management in grasslands are two humaninduced activities recognized by the IPCC that potentially sequester C in soils in a sustainable way (IPCC 2000). Models such as Century can therefore be a valuable tool to simulate SOC changes resulting from these improved land management practices in the Sahel, as both of these events can be integrated in the model. Even if estimating historical or current SOC levels is somewhat problematic, modeling changes in SOC from a given baseline may be accurate. Such studies can lead to the identification of improved practices, which are, at the same time, environmentally and socioeconomically appropriate (Tschakert 2001, Olsson and Ardö 2002). One remaining problem is to identify from what baseline changes over time should be compared (Brown and Hall 2002).

\section{Conclusions}

Data uncertainties in the modeling of the historical soil C levels cause considerable uncertainties in the estimation of current or future SOC levels. The estimation of the current SOC level varied by up to $\pm 20 \%$ (40 
$\mathrm{g} / \mathrm{m}^{2}$ ) from the average, due to uncertainties regarding fire return intervals, grazing intensities and climate. Modeling with soil texture derived from the FAO Soil Map of the World and the IGBP Soil Data Task resulted in SOC roughly $50 \%$ and $33 \%$ larger than modeling with texture derived from soil samples.

\section{Acknowledgements}

We would like to thank the staff at the Natural Resource Ecology Laboratory of Colorado State University, especially Cindy Keough, for providing the Century model and offering support regarding its usage and methods. This work was supported by the Swedish Research Council (621-2001-1806) and the Crafoord Foundation (Ref. No. 00782). The constructive comments from the reviewers significantly improved the manuscript.

\section{Appendix 1. CENTURY Variables Mentioned in Text $^{\mathrm{a}}$}

\begin{tabular}{ll} 
Table A1 & Testing. \\
\hline $\begin{array}{l}\text { CENTURY } \\
\text { variables }\end{array}$ & Description \\
\hline som1c $(2)$ & C in active soil organic matter $\left(\mathrm{g} / \mathrm{m}^{2}\right)$ \\
som2c & C in slow pool soil organic matter $\left(\mathrm{g} / \mathrm{m}^{2}\right)$ \\
som3c & C in passive soil organic matter $\left(\mathrm{g} / \mathrm{m}^{2}\right)$ \\
Somsc & Sum of labeled and unlabeled $\mathrm{C}$ from \\
& som1c $(2)$, som2c and som3c $\left(\mathrm{g} / \mathrm{m}^{2}\right)$ \\
flgrem & Fraction of live shoots removed by a grazing \\
& event \\
fdgrem & Fraction of standing dead removed by a \\
& grazing event \\
Grzeff & Effect of grazing on production \\
snfxmx $(2)$ & $\begin{array}{c}\text { Symbiotic } \mathrm{N} \text { fixation maximum for trees } \\
\text { ( } \mathrm{g} \text { N fixed } / \mathrm{g} \text { C net production) }\end{array}$ \\
&
\end{tabular}

${ }^{\mathrm{a}}$ From Metherell and others (1993).

\section{References}

Adderley, W. P., I. A. Simpson, J. Lockheart, R. P. Evershed, and D. A. Davidson. 2000. Modeling traditional manuring practices: soil organic matter sustainability of an early Shetland community?. Human Ecology 28:415-431.

Ahlcrona, E. 1988. The impact of climate and man on land transformation in central Sudan. Lund, PhD thesis. Lund University Press, Lund, 140 pp.

Alstad, G. 1991. The influence of Acacia tortilis on soil in arid north-eastern Sudan. University of Bergen, Bergen, Norway, 79 pp.

Anonymous. 1999. Estimation and monitoring of carbon sequestration in Gireigikh community based range land project. Final report SUD/93/G31. UNDP, Khartoum, 60 pp.
Ardö, J., and L. Olsson. 2003a. Assessment of soil organic carbon in semi-arid Sudan using GIS and the Century model. Journal of Arid Environment 54:633-651.

Ardö, J., and L. Olsson. 2003b. Soil carbon sequestration in traditional farming in Sudanese drylands. Environmental Management (in press).

Ardö, J., A. Barkman, and P. Arvidsson. 2000. Critical levels of $\mathrm{SO}_{2}$ in northern Czech Republic-uncertainties and relationship to regional forest decline. Geographical and Environmental Modelling 4:131-161.

Bationo, A., and A. Buerkert. 2001. Soil organic carbon management for sustainable land use in Sudano-Sahelian West Africa. Nutrient Cycling in Agroecosystem 61:131-142.

Bromberg, J. G., R. McKeown, L. Knapp, T. G. F. Kittel, D. S. Ojima, and D. S. Schimel. 1996. Integrating GIS and the Century model to manage and analyze data. GIS and Environmental Modeling: Progress and Research Issues: 00:429-431.

Brown, S., and M. Hall 2002. Development and comparison of approaches for establishing baseline scenarios for land-use change and forestry projects. Page 41 in Proceedings of USDA symposium on natural resource management to offset greenhouse gas emissions. Raleigh, North Carolina.

Burke, I. C., C. M. Yonker, W. J. Parton, C. V. Cole, K. Flach, and D. S. Schimel. 1989. Texture, climate, and cultivation effects on soil organic matter context in U.S. grassland soils. Soil Science Society of America Journal 53:800-805.

Craig, G. M. 1991. The agriculture of the Sudan. Oxford University Press, Oxford 450.

Davies, H. R. J. 1985. Natural resources and rural development in arid lands: case studies from Sudan. United Nations University Press, Tokyo 94.

Devendra, C., and G. B. McLeroy. 1982. Goat and sheep production in the tropics. Longman Group, . 271.

DOXIADIS 1964. Land and water use survey in Kordofan province of the Republic of the Sudan. DOX-SUD-A25. Doxiadis Associates, Athens, Greece 232.

Elagib, N. A., and M. G. Mansell. 2000. Recent trends and anomalies in mean seasonal and annual temperatures over Sudan. Journal of Arid Environments 45:263-288.

Falloon, P. D., P. Smith, J. U. Smith, J. Szabo, K. Coleman, and S. Marshall. 1998. Regional estimates of carbon sequestration potential: linking the Rothamsted carbon model to GIS databases. Biology and Fertility of soils 27:236-241.

Falloon, P. D., P. Smith, J. Szabo, and L. Pásztor. 2002. Comparision of approaches for estimating carbon sequestration at the regional scale. Soil Use and Management 18:164-174.

FAO-UNESCO. 1995. The digital soil map of the world (DSMW). Paris, FAO-UNESCO.

Global Soil Data Task (2000). Global Soil Data Products CDROM (IGBP-DIS). Available online at http://www.daac.ornl.gov/ from the ORNL Distributed Active Archive Center, Oak Ridge National Laboratory, Oak Ridge, Tennessee, USA, International Geosphere-Biosphere ProgrammeData and Information Services.

Haaland, G. 1991. Production systems in western Sudan. Pages 230-251 in G. M. Craig Eds, The agriculture of the Sudan. Oxford University Press, Oxford. 
Hulme, M. 2001. Climatic perspectives on Sahelian desiccation: 1973-1998. Global Environmental Change 11:19-29.

Humphreys, L. R. 1978. Tropical pastures and fodder crops. Longman Group, . 135.

IPCC 2000. Land use, land-use change, and forestry. Cambridge University Press, Cambridge 377.

Jewitt, T. N., and J. S. Manton 1954. Soil exhaustion in the Goz sands of the Sudan. Page 413-416 in Proceedings of Congres international de la science du sol, Leopodville.

Khogali, M. M. 1991. Famine, desertification and vulnerable populations: the case of Umm Ruwaba District, Kordofan region, Sudan. Ambio 20:204-206.

Kyoto Protocol. 1997. Kyoto Protocol to the United Nations Framework Convention on Climate Change. FCCC/CP/ 1997/7/Add.1, Decision 1/CP.3, Annex, 7.

Lal, R. 2001. Potential of desertification control to sequester carbon and mitigate the greenhouse effect. Climatic Change 51:35-72.

Lal, R. 2002. Soil carbon dynamics in cropland and rangeland. Environmental Pollution 116:353-362.

McDowell, N. 2002. Developing countries to gain from carbon-trading fund. Nature 420:4.

Metherell, A. K., L. A. Harding, C. V. Cole, and W. J. Parton. 1993. Century soil organic matter model environment, technical documentation, agroecosystem version 4.0. Technical Report No. 4, United States Department of Agriculture, Agricultiral Research Service, Great Plains System Research Unit, $250 \mathrm{pp}$.

Mitchell, S. W., and F. Csillag. 2001. Assessing the stability and uncertainty of predicted vegetation growth under climate variability: northern mixed grass prairie. Ecological Modelling 00:101-121.

Nicholson, S. E. 2000. The nature of rainfall variability over Africa on the time scales of decades to millenia. Global and Planetrary Change 26:137-158.

Ojima, D. S., W. J. Parton, D. S. Schimel, T. G. F. Kittel, and J. M. O. Scurlock. 1993. Modeling the effects of climatic and $\mathrm{CO}_{2}$ changes on grassland storage of soil C. Water, Air, and Soil Pollution 70:643-657.

Olsson, K. 1985a. Remote sensing for fuelwood resources and land degradation studies in Kordofan, The Sudan. PhD thesis. Lund University, Lund, 182 pp.

Olsson, K., and A. Rapp. 1991. Dryland degradation in central Sudan and conservation for survival. Ambio 20:192-195.

Olsson, L. 1985b. An integrated study of desertification. PhD thesis. Lund University, Lund, 170 pp.

Olsson, L., and J. Ardö. 2002. Soil carbon sequestration in degraded semiarid agro-ecosystems-perils and potentials. Ambio 31:471-477.

Pacheco, R., and H. A. Dawoud. 1976. Exploratory soil survey of north and south Kordofan. Soil Survey Report 81. UNDP, Khartoum, 105 pp.

Parton, W. J., D. S. Schimel, C. V. Cole, and D. S. Ojima. 1987. Analysis of factors controlling soil organic levels of grasslands in the Great Plains. Soil Science Society of America Journal 51:1173-1179.

Parton, W. J., J. W. B. Stewart, and C. V. Cole. 1988. Dynamics of C, N, P and S in grasslands soils: a model. Biogeochemistry 5:109-131.

Parton, W. J., J. M. O. Scurlock, D. S. Ojima, T. G. Gilmanov, R. J. Scholes, D. S. Schimel, T. Kirchner, J. C. Menaut, T. Seastedt, E. Moya, G., A. Kamnalrut, and J. I. Kinyamario. 1993. Observations and modeling of biomass and soil organic matter dynamics for the grassland biome worldwide. Global Biogeochemical Cycles 7:785-809.

Parton, W. J., D. S. Ojima, and D. S. Schimel. 1994. Environmental change in grasslands: assessment using models. Climatic Change 28:111-114.

Parton, W. J., M. B. Coughenour, J. M. O. Scurlock, D. S. Ojima, T. G. Gilmanov, R. J. Scholes, D. S. Schimel, T. B. Kirchner, J.-C. Menaut, T. R. Seastedt, E. Garcia Moya, A Kamnalruth, J. I. Kinyamario, and D. O. Hall. 1996. Global grassland ecosystem modelling: development and test of ecosystem models for grassland systems. Page 229-279. in A. I. Breymeyer, D. O. Hall, J. M. Mellilio, and G. I. ÅAgren. Eds, Global change: effects on coniferous forests and grasslands. John Wiley \& Sons, New York.

Paustian, K., E. Levine, W. M. Post, and I. M. Ryzhova. 1997. The use of models to integrate information and understanding of soil $\mathrm{C}$ at the regional scale. Geoderma 79:227-260.

Pennock, D. J., and A. H. Frick. 2001. The role of field studies in landscape-scale applications of process models: an example of soil redistribution and soil organic carbon modeling using Century. Soil and Tillage Research 58:183-191.

Poussart, J.-N. 2002. Verification of Soil Carbon Sequestration-uncertainties of Assessment Methods. MSc thesis. Lund University, Lund, $73 \mathrm{pp}$.

Robert, M. 2001. Soil carbon sequestration for improved land management. World Soil Resources Reports 96, Food and Agriculture Organization of the United Nation (FAO), Rome, $60 \mathrm{pp}$.

Sanchez, P. A. 2002. Soil fertility and hunger in Africa. Science 295:2019-2020.

Scholes, R. J., and B. H. Walker. 1993. An African savanna. Synthesis of the Nylsvley study. Cambridge University Press, Cambridge 306.

Sitch, S. 2000. The role of vegetation dynamics in the control of atmospheric $\mathrm{CO}_{2}$ content. PhD thesis. Lund, Lund University, $29 \mathrm{pp}$.

Smith, P., J. U. Smith, D. S. Powlson, W. B. McGill, J. R. M. Arah, O. G. Chertov, K. Coleman, U. Frankoe, S. Frolking, D. S. Jenkinson, L. S. Jensen, R. H. Kelly, H. Klein-Gunnewiek, A. S. Komarov, C. Li, J. A. E. Molina, T. Mueller, W. J. Parton, J. H. M. Thornley, and A. P. Whitmore. 1997. A comparision of the performance of nine soil organic matter models using datasets from seven long-term experiments. Geoderma 81:153-225.

Stephenne, N., and E. F. Lambin. 2001. A dynamic simulation model of land-use changes in Sudano-sahelian countries of Africa (SALU). Agriculture, Ecosystems and Environment 85:145-161.

Stern, M. 1985. Census from Heaven? PhD-thesis. Lund University, Lund $128 \mathrm{pp}$.

Tschakert, P. 2001. Human dimensions of carbon sequestration: A political ecology approach to soil fertility manage- 
ment and desertification control in the Old Peanut Basin of Senegal. Arid Lands Newsletter May-June.

UNEP 1992. World atlas of desertification. UNEP, Nairobi, Kenya 87.

Warren, A. 1970. Dune trends and their implications in the central Sudan. Zeitshrift fur Geomorphologie Supplementband 10:154-180.
Warren, A., Y. C. Sud, and B. Rozanov. 1996. The future of deserts. Journal of Arid Environments 32:75-89.

Zaroug, M. G. 2000. Country Pasture/Forage Resouce Profiles - Sudan. Grassland and Pasture Crops, Plant Production and Protection Division, Food and Agriculture Organization of the United Nations, $50 \mathrm{pp}$. 